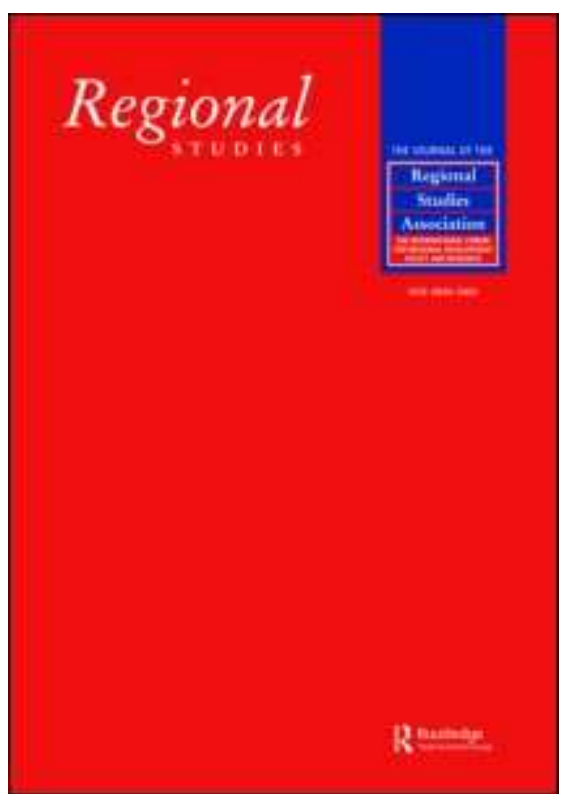

\title{
Scientific mobility and knowledge transfer at the interregional and intraregional level
}

\begin{tabular}{|r|l|}
\hline Journal: & Regional Studies \\
\hline Manuscript ID: & CRES-2010-0042.R1 \\
\hline Manuscript Type: & Special Issue Paper \\
\hline JEL codes: & $\begin{array}{l}\text { J61 - Geographic Labor Mobility } \mid \text { Immigrant Workers < J6 - Mobility, } \\
\text { Enemployment, and Vacancies < J - Labor and Demographic } \\
\text { and Development < O - Economic Development, Technological } \\
\text { Change, and Growth, R10 - General < R1 - General Regional } \\
\text { Economics < R - Urban, Rural, and Regional Economics }\end{array}$ \\
\hline Keywords: & $\begin{array}{l}\text { star scientists, scientific mobility, interregional and intraregional } \\
\text { knowledge transfer }\end{array}$ \\
\hline
\end{tabular}

\section{SCHOLARONE" Manuscripts}


Scientific mobility and knowledge transfer at the interregional and intraregional level

\author{
Michaela Trippl \\ Institute for Regional Development and Environment, Vienna University of Economics and \\ Business, Nordbergstrasse 15, A-1060 Vienna, Austria \\ Email: michaela.trippl@wu.ac.at
}

(Received January 2010: in revised form December 2010) 


\begin{abstract}
The aim of this paper is to explore the extent and nature of knowledge flows which result from the international mobility of elite scientists. Based on the findings from a worldwide survey of 'star scientists' (i.e. authors of highly-cited journal articles in different research areas), it is shown that these top researchers establish manifold interregional knowledge links between their sending and receiving areas and embed themselves in their location of choice by creating connections to regional actors. Furthermore, the paper identifies a set of crucial factors that determine whether or not star scientists engage in intraregional knowledge transfer activities.
\end{abstract}

Keywords: star scientists, scientific mobility, interregional and intraregional knowledge transfer

JEL classification: J61, O30, R10 


\section{Introduction}

Migration and international movements of highly-skilled people in general and scientists in particular have grown considerably in the last years (OECD, 2005; SKELDON, 2009). It is widely recognised that well-educated individuals are important 'carriers of knowledge', transferring expertise and know-how from place to another by means of their mobility. The international mobility of skilled people and the knowledge flows related to their movements can have far reaching effects on the innovation capacities of the regions involved in such processes. Despite a growing interest in this topic, the key features of knowledge circulation through mobile talent and the specific modes of interregional and intraregional knowledge transfer remain poorly understood, however.

The focus of this paper is on international scientific mobility, more precisely on movements of the world's 'star scientists'. Star scientists are defined here as authors of highly-cited research papers, identified by the number of citations they generated in journals in the ISI databases in the period 1981-2002. These outstanding individuals are possessors of unique cutting-edge scientific knowledge and expertise. However, only few scholars have looked at the international mobility of elite scientists and little is known about the extent and character of knowledge transfer which result from their movements.

The central aim of this paper is to contribute to a deeper understanding of this phenomenon by exploring the link between the international mobility of world-class researchers and knowledge flows. Based on the findings from a survey of 720 star scientists (including 375 internationally mobile stars) the paper investigates the extent and nature of interregional and intraregional knowledge transfer activities performed by these stars. Both scientific linkages and connections to the industrial sector will be analysed. More specifically, the following research questions will be dealt with. 
- To what extent do mobile star scientists create or maintain knowledge links to the scientific community and to firms at their prior locations? What are the dominating modes of interregional knowledge transfer between the sending and receiving areas of these stars?

- To what degree and in which ways do star scientists engage in intraregional knowledge transfer activities at their current location? Which factors influence whether or not stars embed themselves in their current region of choice by establishing knowledge linkages to regional actors and organisations?

The remainder of the paper is structured as follows. Section 2 presents a short literature on geographical movements of highly-skilled people and knowledge transfer. This is followed by the discussion of a simple 'knowledge link model' that illuminates in a conceptual way the relation between spatial movements of star scientists and resulting knowledge flows both at the interregional and intraregional level. Section 3 contains the description of the sample and some methodological notes. Section 4 presents the results of the empirical analyses. Finally, section 5 summarises the key findings and points to further research questions.

\section{Literature Review and Conceptual Approach}

Academics and researchers play an increasingly important role in regional innovation and knowledge-based development (HOROWITZ, 1966; FURUKAWA and GOTO, 2006; THORN and HOLM-NIELSEN, 2008; BABA et al., 2009). Like other skilled people, scientists tend to be highly mobile at an international scale and their movements can involve a substantial transfer of knowledge and expertise. International scientific mobility is regarded as a normal phenomenon in the academic world (MEYER et al., 2001). LAUDEL (2003, p. 215) noted that 'scientists 'on the move' bring their knowledge to other places, acquire new 
knowledge in the new place and thus promote new combinations of knowledge. This is especially important if knowledge is not communicated through other channels like publications ...' Movements of scientists and knowledge flows which result from their mobility can have far reaching effects for the regions involved in such processes. Scientific migration and mobility are a complex phenomenon. The effects of scientific mobility depend on factors such as the skill levels involved and the temporal character of such movements (see also ACKERS and GILL, 2005). However, empirical evidence about the international mobility of elite researchers is scarce (LAUDEL, 2005; HUNTER et al., 2009) and little is still known about the nature of knowledge flows and the regional consequences which result from the geographical mobility of outstanding researchers.

\subsection{Mobility of highly-skilled people and knowledge transfer}

Several authors have argued that the mobility of highly-qualified individuals represents a core mechanism for the spilling over and transfer of (embodied) knowledge (ARROW, 1959; ROSENKOPF and ALMEIDA, 2003; MOEN, 2005; DÖRING and SCHNELLENBACH, 2006). Looking at the geography of knowledge transfer through mobile labour, empirical research has highlighted that both the regional and global levels matter.

Movements of skilled workers between local firms and universities are regarded to constitute a central mechanism of localised knowledge transfer (SAXENIAN, 1994; KEEBLE 2000; LAWTON SMITH and WATERS, 2005), underpinning the dynamic development of hightechnology regions. Labour mobility, however, is not restricted to the local or regional level. Recent contributions in migration studies point to an increase of the global mobility of highlyskilled scientists, managers, and engineers (OECD, 2005, SKELDON, 2009). Migration and international mobility of top experts are acknowledged to be powerful mechanisms for the global diffusion of cutting-edge scientific, technical and managerial knowledge (WILLIAMS, 
2007; OECD, 2008). The literature suggests that international knowledge flows through mobile talent are far from being one way flows but tend to be multidirectional in nature, leading to a sharing of the benefits of skilled migration between sending and receiving areas (REGETS, 2007; KERR, 2008). This finding challenges the traditional dichotomy between 'brain drain' and 'brain gain' when assessing the consequences of international migration of skilled workers. The notion of 'brain circulation' (SAXENIAN, 2005) seems to more adequate to describe the current situation. The shift from longer-term migration to shorterterm mobility (WILLIAMS et al., 2004) and the return of highly-qualified people to their home countries (SAXENIAN 2005) represent important examples in this context. Recent academic work demonstrated that the sending countries or regions might also benefit from their top experts even if they do not return. The rise of diaspora networks which connect skilled expatriates with their country of origin (ACKERS, 2005; GILL, 2005) is relevant in this context. KERR (2008) highlighted potential benefits from high-skilled migration for sending countries, showing that ethnic and entrepreneurial communities in the United States play an important role for international technology transfer to their home countries. Thus, the literature provides some indication that skilled people who relocate maintain or create knowledge links to their home base. This idea is also supported by AGRAWAL et al. (2006) who identified knowledge flows from the region that receives mobile employees to the region that lost these people. Analysing patent data, AGRAWAL et al. (2006) demonstrated that social ties that promote knowledge transfer persist even after formerly co-located inventors are separated (see also OETTL and AGRAWAL, 2008). JÖNS (2009) investigated the longterm effects of research stays spent by foreign academics in Germany. She demonstrated that this kind of scientific mobility has led to subsequent academic movements and collaboration, linking Germany to the visiting researchers' home countries. To summarise, there is a strong claim in the literature that the mobility of talent is related to substantial international knowledge flows. What remains somewhat unclear is the relative importance of different 
modes of knowledge transfer that matter in this context. Furthermore, hardly any studies investigated international movements of world-class scientists and flows of knowledge related to their mobility.

Whilst there is little evidence on international knowledge flows set off by mobile top scientists, a few scholars have looked at intraregional knowledge transfer activities performed by elite researchers. ZUCKER and her colleagues have shown that direct involvement of star scientists was pivotal for the rise and transformation of biotechnology and other high-tech sectors (ZUCKER et al., 1998, 2002; ZUCKER and DARBY, 2006). SCHILLER and REVILLA-DIEZ (2010) investigated knowledge transfer activities performed by highly-cited scientists in Germany and provided evidence for rather strong intraregional knowledge links between these stars and local actors. Scientific collaborations, new firm formation and recruitment of staff and $\mathrm{PhD}$ students proved to be strongly localised in nature. Less evidence was found that stars also engage in local collaborations with industry.

In the following an attempt is made to explore both in a conceptual way and empirically the nature of knowledge transfer which results from spatial movements of elite researchers.

2.2 Interregional and intraregional knowledge transfer activities by the scientific elite:

Towards a knowledge link model

Focusing on movements of star scientists and drawing on the insights derived from the literature dealing with mobility related knowledge flows discussed above, this subsection presents a simple model (Figure 1) which lays the conceptual foundations for the empirical analysis in section 4 . The model recognises that mobile star scientists can give rise to a large variety of interregional and intraregional knowledge flows and it explicates important types in this respect. It should be alerted, however, that the strength of such flows as well as the 
consequences for the sending and receiving regions might depend on the scientific and economic specialisation and the knowledge bases of the involved areas, their absorptive capacity as well as the duration of time the star stays in a particular region.

Interregional knowledge transfer

Mobile star scientists can potentially set off manifold knowledge linkages between their sending and receiving regions. From a dynamic perspective it is useful to distinguish between 'initial knowledge flows' and 'subsequent knowledge flows' in this context. Such a view allows for illuminating the complexity of the regional effects which might be related to the geographical mobility of stars. The knowledge link model proposed in this paper takes as a starting point the movement of a star scientist from Region 1 (sending region) to Region 2 (receiving region). Arguably, such a movement leads to an interregional spilling over of knowledge. It would be misleading, however, to take into account only this initial knowledge flow. To eschew an oversimplification of the phenomenon dealt with here, the model assumes that the initial interregional knowledge spillover effect that is due to the movement of a star scientist could entail a range of further knowledge flows between the sending and the receiving region. Subsequent knowledge flows can take different forms. Members of the former research team of the star or talented students may follow the star scientist from region 1 to region 2, thus, generating a further round of interregional knowledge spillovers from the sending to the receiving area. Furthermore, if the star maintains her or his relationships to the academic and industrial sector of the sending region, a backward transfer of knowledge from the receiving region to the sending one or the circulation of expertise between these areas could be released. Several authors (KEEBLE, 2000; SCHARTINGER et al., 2001; TÖDTLING et al., 2006) have elaborated on typologies of different modes (or mechanisms) of knowledge transfer within academia and from universities to industry, which can be 
Intraregional knowledge transfer

Mobile star scientists may also engage in knowledge transfer activities to actors and organisations in their region of choice. By doing so, top researchers embed themselves in their current location ${ }^{1}$. To conceptualise the role of 'embedded star scientists' the model identifies various mechanisms which might be relevant for the transfer of know-how and expertise from these top researchers to regional actors (Figure 1). Top researchers may create linkages to scientists and research organisations located in the region, thus promoting a transfer of their advanced expertise within the regional academic sector. The model distinguishes between two core modes of knowledge transfer within the regional science system. The first mode of knowledge transfer considered here is related to the classic educational function of star scientists. Top scientists are regarded to play an essential role in attracting the best young talents and they guide them into fruitful research areas (MAHROUM, 2003; LAUDEL, 2005). Elite scientists, thus, generate the new scientific elites. If scientific talents trained by star scientists do not move away after having finished their studies but continue to stay in the region to work for other research organisations, the regional academic sector might experience positive effects. 
[Figure 1 about here]

The second key mode of knowledge transfer is associated with scientific collaborations. The more cooperative linkages star scientists maintain with other researchers present in the region, the more vividly will the advanced knowledge possessed by stars circulate at the regional level. Star scientists may also be engaged in knowledge transfer activities to regional companies (see particularly ZUCKER et al. 1998, 2002; SCHILLER and REVILLA-DIEZ, 2010). The model identifies several key mechanisms by which star scientists can supply their knowledge to the regional industry sector. Star scientists might act as a source of highlyqualified workers for regional firms. Movements of skilled students who have been educated by stars to companies constitute a significant mode of knowledge transfer, supporting the regional diffusion and commercial application of new scientific expertise. Formal and informal collaborations (R\&D projects, university-industry partnerships, etc.) between star scientists and companies represent another key mode of intraregional knowledge transfer. Moreover, the region might also benefit from more direct forms of commercialisation of the scientific knowledge embodied in top researchers. This holds in particular true if stars sell patents to regional firms, work part of their time for regional companies as member of the management or advisory board, or even establish their own business in the region. Arguably, the latter three mechanisms require high levels of engagement by stars.

Knowledge flows related to movements of star scientists may have far reaching effects for both the sending and receiving regions. It can be assumed that the receiving region of a star scientist benefits from a strengthening of the science base and the industry sector, whilst the sending region is likely to experience a weakening of its scientific and economic capabilities. This initial effect is reinforced if the 'follower phenomenon' is quantitatively and 
qualitatively strong. Provided that the mobile star scientist does not cut all ties to her or his former home region a backward knowledge transfer and interregional circulation of knowledge can set in, stimulating scientific progress and economic development in both the sending and receiving area. The receiving region will in particular benefit from the immigration of star scientists, if their knowledge diffuses locally. As noted above, this requires an embedding of the star into the regional scientific community and an intensive knowledge transfer to regional firms. Consequently, only 'embedded stars' who establish a range of contacts to actors in the host region can act as an engine of growth, whilst 'isolated stars', i.e. those who lack such essential linkages will probably set off fewer economic effects. It is beyond the scope of this paper to measure the regional effects just outlined above. Rather the paper aims at analysing to what extent star scientists potentially contribute to regional development by engaging in interregional and intraregional knowledge transfer activities.

\section{Data and Methodology}

In order to identify top researchers the database 'ISI Highly Cited' was used. This database contains information about 5,600 'star scientists' (defined as authors of highly-cited research papers), who belong to the world's most renowned scientists. The importance of contribution to scientific progress made by these stars is identified by the number of citations they generated in journals in the ISI databases. The information in ISI Highly Cited is based on publications and citations from the period 1981-2002. ISI Highly Cited distinguishes between 21 different areas of research (subject categories) such as clinical medicine, engineering, physics or social sciences and identifies approximately the 250 most cited individuals in each category.

To gather data on the mobility of top researchers and their knowledge sharing activities a worldwide web-based survey of ISI highly cited star scientists was employed. The survey was 
conducted in the year 2008. All 3,274 star scientists who provide their contact information (email address) in the database have been requested to participate in the study. 433 stars could not be approached due to invalid email addresses. Out of the remaining 2,841 star scientists, 720 filled in the questionnaire, yielding a response rate of $25.3 \%$. The respondents include 181 expats (25\%), 194 returnees (27\%) and 345 non-movers (48\%). Consequently, $52 \%$ of the responding star scientists have an international mobility background ${ }^{2}$. Expatriates are referred to here as scientists who left their home countries to work at a foreign location. Returnees are defined here as researchers who relocated back home after having lived and worked at a foreign location for a substantial period of time. Finally, non-movers are scientists who have so far not relocated internationally for professional purposes but have stayed in their home countries. Breakdown of the data by mobility type results in small sample sizes. This represents some limitation to this study which has to be kept in mind when discussing the empirical findings (section 4). For data analysis methods of descriptive statistics and multivariate analyses were applied.

[Table 1 about here]

Table 1 shows key sample characteristics of the surveyed top researchers. The sampled mobile stars are predominantly male and more than $50 \%$ of them are older than 60 years. A sizeable fraction of expatriates and returnees $(70 \%)$ is employed by universities and about $20 \%$ of them are working for a non-university research institution. The proportion of mobile star scientists from the corporate sector is negligible ${ }^{3}$. The mobile top researchers $(44 \%$ of expats, $54 \%$ of returnees) included in the sample are strongly oriented towards basic research. Looking at the scientific disciplines ${ }^{4}$ one can observe some differences between the two groups of mobile scientists. More than $55 \%$ of the sampled expatriates are working in the field of natural sciences, about $14 \%$ in engineering and technology and another $16 \%$ in 
medical and health sciences. Like expatriates, $56 \%$ of the responding returnees are natural scientists. However, compared to expats, a lower share of returnees is working in engineering and technology (9\%) and a higher share in medical and health sciences (25\%). Other categories (social science, agricultural science) play only a minor role. Chi-square tests show that differences among expatriates and returnees regarding gender, type of research, type of institution, and science groups are not statistically significant. For reasons of comparison Table 1 also contains characteristics of non-movers. This group of stars does not differ in statistically significant ways from their mobile counterparts in terms of gender, age, affiliation and type of research. Chi-square tests indicate that only the hypothesis that the distribution of expats, returnees and non-movers across science groups is the same can be rejected (at the 5 $\%$ level of significance). In contrast to mobile stars, the share of non-movers working in the field of natural sciences is lower whilst the proportion of non-movers engaged in medical and health sciences is higher, particularly when compared to expats.

Table 1 also provides data on the temporal aspect of mobility of expatriates and returnees, pointing to considerable differences between these two groups of stars. The average time period that expats have already spent away from their home regions amounts to 30 years. This reflects a pattern of permanent migration. Returnees, in contrast, have spent on average six years abroad before returning to their home countries and regions. Movements of returnees are thus best described as temporary migration.

The star scientists included in the sample are strongly concentrated in a few places worldwide. US cities and regions - in particular global centres of scientific excellence such as Cambridge, MA, Stanford, New York and Boston - are successful in retaining non-movers and attracting expatriates (see Tables 7 and 9 in the annex). At the same time they are amongst the key sending regions of returnees, i.e. the places where foreign stars worked for a 
while before relocating back home (Table 8 in the annex). The top 8 host areas (i.e. receiving regions) of expats are all located in the United States and host not fewer than $22 \%$ of all surveyed expatriates. Interestingly, only seven places (including scientific powerhouses in Europe such as London and Cambridge) account for the outflow of nearly one quarter of all expats (see Table 7 in the annex). Looking at the geography of returnees, a different picture is found. It is particularly cities and regions in Japan (Tokyo and Kyoto) and various places in Europe (such as Munich, Copenhagen and London) where a strong inflow of star scientists who move back home could be observed. Also returnees show a pattern of strong agglomeration. The top 8 ranked home regions (i.e. receiving regions) account for $21 \%$ of all sampled returnees (Table 8 in the annex).

\section{Empirical Results}

This section investigates the degree and nature of interregional knowledge transfer activities (i.e. international knowledge flows between the sending and receiving areas) of mobile stars. Furthermore, it will be examined to what extent these stars are engaged in knowledge transfer activities at the intraregional level, i.e. in their current region of choice (defined as the subnational area where they are currently located). Finally, this section also identifies a set of factors that influence whether or not stars engage in intraregional knowledge transfer activities.

\subsection{Interregional knowledge transfer}

To what extent do mobile top researchers sustain or create linkages to the scientific community and to the industrial sector at their former location, thus propelling an interregional flow of knowledge between their sending and receiving regions? The stars included in the sample keep close connections to the science system of their sending regions. Not fewer than $82 \%$ of the surveyed expatriates reported maintaining knowledge linkages to 
the scientific community in their home regions. Returnees are even more engaged in interregional knowledge exchange with scientists at their prior host region. Not less than $90 \%$ still have contacts with the scientific community at their former location. A Chi-square test shows that these differences between expats and returnees are statistically significant (at the 5\% level). To summarise, there is a substantial interregional knowledge transfer between distant research systems triggered by the surveyed world-class scientists. Obviously, returnees play a more powerful role in this respect than expatriates.

Which mechanisms are employed by star scientists to promote an interregional knowledge flow between their sending and receiving regions? As revealed in Table 2, the joint attendance of international scientific conferences and workshops ( $71 \%$ of expatriates, $82 \%$ of returnees) and research visits and staff exchange (70\% of expatriates, $82 \%$ of returnees) play the most important role, but also joint publications (64\% of expatriates, $79 \%$ of returnees) are rather common modes of scientific knowledge transfer. Similar shares were found to exchange knowledge with scientific actors from the sending regions via research co-operations and joint participation in workshops. As illustrated in Table 2 a range of other modes of knowledge transfer also matters. Furthermore, Table 2 shows that a sizeable fraction of stars is even strongly engaged in interregional knowledge transfer activities, i.e. they adopt various mechanisms regularly or frequently. Only joint patenting activities are rather uncommon.

[Table 2 about here]

As noted earlier, mobile top researchers might also set in motion movements of other research talent, if former colleagues and students follow the stars to their new location. This specific type of 'subsequent knowledge flow' which has been referred to as 'follower phenomenon' (see section 2.2) seems to be quite common for the sampled star scientists. Remarkably, more 
than $30 \%$ of the expatriates and $45 \%$ of the returnees stated that their own movement abroad (expatriates) or back home (returnees) triggered further movements of followers (scientists or students) from their previous location.

In a next step it is intriguing to explore whether or not the surveyed star scientists also have connections to firms at their former location, thus contributing to the industrial exploitation of scientific research at the international scale. A sizeable fraction of expatriates (19\%) reported maintaining knowledge links to companies in their home regions. Looking at the group of returnees it can be observed that about $35 \%$ of them have linkages to firms in their prior host region. A Chi-square test shows that these differences between expatriates and returnees are statistically significant at the $1 \%$ level.

\begin{abstract}
Analysing the modes of knowledge transfer highlights that star scientists tend to employ a large variety of different mechanisms to exchange knowledge with companies at their prior location (Table 3). Similar to scientific ties there is no single dominant type of knowledge flow but manifold modes of interregional knowledge transfer to companies matter. Key modes include research co-operations (15\% of expats, $26 \%$ of returnees), consulting services ( $16 \%$ of expats, $24 \%$ of returnees) and contract research (12\% of expats, $22 \%$ of returnees), Similar shares of expats and returnees transfer knowledge to firms at their previous location via research visits and staff exchange as well as the joint participation in scientific conferences and workshops. However, hardly any mechanisms listed in Table 3 are used in strong ways, i.e. on a regular or frequent basis.
\end{abstract}

[Table 3 about here] 
The evidence provided above suggests that mobile star scientists give rise to a large variety of interregional knowledge linkages, implying that both their sending and receiving regions potentially benefit from the stars' movements through enhanced knowledge transfer. A considerable share of the surveyed top researchers creates or maintains connections to the scientific community at their former locations and to a lesser extent star scientists are also linked to firms at these places. Furthermore, it was shown that stars employ a wide spectrum of different modes of knowledge transfer. Returnees proved to be significantly more involved in such knowledge transfer activities than expatriates. It is beyond the scope of this paper to look at these differences in detail. There might be various reasons for this pattern, such as the long period of time that many expats have already spent abroad (this would indicate a decrease of social proximity over time) or the lack of appropriate partners in the home regions of expatriates.

\subsection{Intraregional knowledge transfer}

As argued in section 2.2 the inflow of top researchers might have far reaching effects for the receiving region. Apart from gaining access to distant knowledge sources through the stars' interregional knowledge links, the receiving region might take additional advantages from the arrival of stars, if they engage in intraregional knowledge transfer activities. In this section it will be analysed as to what extent mobile star scientists embed themselves in their region of choice (defined as the sub-national area where they are currently located) by creating knowledge linkages to regional actors and organisations. Furthermore, the relative importance of different modes of intraregional knowledge transfer will be analysed. Here data availability allows for comparing intraregional knowledge transfer activities performed by mobile top researchers with those performed by non-movers. In the following, a very simple definition of 'embeddedness' is used. Stars who adopt at least one of the seven mechanisms of intraregional knowledge transfer shown in Table 4 in strong or weak ways are referred to as 
'embedded stars'. The results suggest that a large majority of the surveyed star scientists can be classified as embedded stars.

[Table 4 about here]

The sampled elite researchers are strongly engaged in knowledge transfer activities within the scientific community of their regions of choice. Nearly all expats and returnees collaborate with academic institutions at the regional level; more than $60 \%$ of them even do so in a quite strong way. A considerable share of both expatriates (85\%) and returnees (89\%) also indicated that some of their former students are employed by research organisations in the region. There is thus a knowledge transfer via the mobility of talented students educated by the surveyed top researchers. As shown in Table 4 the sampled stars also employ a range of mechanisms to transfer their knowledge and expertise to the regional industry sector. Key modes in this context include R\&D partnerships with firms located in the same region $(73 \%$ of expatriates, $76 \%$ of returnees) and the provision of skilled graduates (67\% of expatriates, $79 \%$ of returnees). However, it should also be mentioned that a relatively large number of star scientists use these modes in quite sporadic and weak ways. Some star scientists are also more directly engaged in the commercialisation of their scientific discoveries by selling patents ( $28 \%$ of expatriates, $32 \%$ of returnees) to regional firms (however, only very few stars carry out this activity regularly or frequently), acting as a member of the management or advisory board of regional firms ( $28 \%$ of expatriates, $27 \%$ of returnees) or even running their own regionally based business (15\% of expatriates, $14 \%$ of returnees). Consequently, star scientists are strongly embedded in their regional economies. There is a large variety of mechanisms by which star scientists potentially influence regional growth and innovation. 
A comparison of the two groups of mobile top researchers reveals that returnees seem to be slightly more engaged in intraregional knowledge sharing activities than expatriates. Chisquare tests show, however, that these differences between expatriates and returnees are only statistically significant (at the 1\% level) for the category 'source of highly-qualified labour'. Another interesting result shown in Table 4 that will be discussed further below (see section 4.3.) concerns the finding that mobile stars do hardly differ in their regional knowledge transfer activities from non-movers.

\subsection{Determinants of intraregional knowledge transfer activities}

The previous subsection provided evidence that star scientists are rather strongly engaged in intraregional knowledge transfer activities. However, the factors which have an influence on whether or not top researchers embed themselves in their regions of choice by employing different modes of knowledge transfer remain unclear. Is the international mobility background of stars really irrelevant for their regional embeddedness as the descriptive analysis suggests? Data availability also allows for addressing a set of further questions. Do stars who maintain interregional knowledge links (see section 4.1) also show a high propensity to engage in intraregional knowledge transfer, i.e. is there a complementary or substitutive relation between interregional and intraregional knowledge transfer activities? Which role do the stars' age, gender, affiliation, discipline and the type of research (basis versus applied research) play? One might expect, for example, that knowledge transfer activities are more likely in some disciplines than in others and that a focus on applied research has a positive impact on the embeddedness of stars. Finally, does location matter? Do US-based stars supply more knowledge to regional actors than stars located elsewhere as some parts of the literature suggest (MOWERY et al., 2001)? 
A multivariate model is used with indicators of the star scientists' employment of various modes of intraregional knowledge transfer as dependent variables and a set of factors as explanatory variables. Table 5 represents the description of the different variables. The dependent variables are binary indicators representing whether or not the respective star scientist adopts a specific mode of knowledge transfer. The explanatory variables include the factors interregional linkages, the mobility background of the surveyed stars, the type of institution they are working for, the degree of applied research, the scientific discipline, and the stars' gender, age and location. A binary logit model is employed.

[Table 5 about here]

The binary logit model presented in Table 6 is weak in explaining whether or not stars are engaged in intraregional knowledge transfer to the academic world in their current location. This has to do with the fact that such activities are ubiquitous in nature. The multivariate analysis, however, provides some interesting insights into those factors that have an influence on intraregional knowledge transfer activities to the industrial world.

[Table 6 about here]

The model provides some indication for the existence of a substitutive relation between interregional scientific linkages and intraregional knowledge transfer. It is, however, only for the activities 'selling patents to firms' and 'entrepreneur' where this pattern proves to be statistically significant (at a $10 \%$ level). Interregional linkages to firms, in contrast, have a positive and significant effect on regional knowledge transfer (via selling patents, becoming an entrepreneur or acting as a board member in firms). The type of institution, i.e. a star's affiliation, also matters in a statistically significant way for some modes of knowledge 
transfer. As one might expect, stars working in a non-university research unit are less likely to be a source of highly-qualified labour than university-based stars, and stars from the corporate sector are more likely to become an entrepreneur than stars working at universities. Next, the type of research has a significant effect on intraregional knowledge transfer to the industrial world. The more applied the research done by star scientists, the likelier it is that they engage in such activities. The scientific discipline also has an influence on whether or not stars transfer their knowledge to regional firms. Star scientists working in natural sciences, engineering $\&$ technology and medical $\&$ health sciences are more likely to engage in the activities 'R\&D projects with firms' and 'selling patents to firms' than top researchers working in social sciences. Finally, gender has a significant effect on the activities 'source of highly-qualified workers' and 'R\&D projects with firms'. Female star scientists are thus more engaged in these activities than male stars.

Other factors considered in the model do not play a role in explaining the embeddedness of stars via intraregional knowledge transfer activities. The model confirms the finding reported in the previous section that the international mobility background of star scientists has a nonsignificant effect on such activities. This result allows for the conclusion that the sending regions of mobile stars, indeed, lose a potential key source of regional development while the receiving areas gain such a source. Given the finding that mobile and non-mobile stars do not differ significantly in their embeddedness, one might even argue that attraction of mobile stars may compensate for the lack of home-grown ones. Another instructive result is that the location of stars hardly suggests significant impact. This result is surprising, given the view in the literature that the United States offer more favourable conditions for and have a longer history of knowledge flows from academia to industry and the commercialisation of scientific knowledge than other parts of the world (see, for instance, MOWERY et al., 2001) . $^{5}$ 


\section{Summary and Conclusions}

In this paper an attempt has been made to explore both conceptually and empirically the relation between movements of 'star scientists' (identified by the number of citations they generated in journals of the ISI databases) and knowledge flows. Star scientists are possessors of unique cutting-edge knowledge. It could be assumed that their mobility has a strong impact on regional development of their sending and receiving areas. However, empirical evidence about movements of the scientific elite is still scarce and, as a consequence, knowledge flows resulting from their mobility remain poorly understood.

The conceptual model proposed in this paper highlighted that mobile scientists can give rise to a substantial knowledge transfer, both at the interregional level (i.e. between the sending and receiving regions of star scientists) as well as at the intraregional level (i.e. in the receiving regions of stars). Empirically, the paper has drawn on the results of a worldwide survey of 720 star scientists. More than 50\% (375 stars) of the sampled top researchers had an international mobility background, being either expatriates or returnees.

Applying methods of descriptive statistics both interregional and intraregional knowledge transfer activities performed by mobile star scientists were analysed. The empirical findings suggested that knowledge flows resulting from scientific mobility are far from being a sporadic phenomenon. The empirical analyses pointed to an important role played by mobile stars in creating knowledge linkages between distant areas. The large majority of both expatriates and returnees maintain linkages to the science system at their former location, thus promoting international transfer of knowledge between their sending and receiving regions. To a lesser extent the surveyed stars also retain connections to firms located in their sending regions. Common modes of interregional knowledge transfer both to scientific actors and firms include joint participation in conferences and workshops, joint publications, as well as 
research visits and staff exchange. But also more formal linkages such as contract research and $R \& D$ collaborations turned out to be relevant. Moreover, it was also demonstrated that the 'follower phenomenon' is quite common, i.e., mobile stars attract further scientific talent to the region.

The evidence provided in this paper suggested that mobile stars do not only promote intraregional knowledge flows but they are also strongly engaged in intraregional knowledge transfer activities. A considerable share of expatriates has embedded themselves in their host regions by creating various connections to regional actors and organisations. Also returnees are strongly involved in knowledge circulation in their home regions, after having worked for some time abroad. Academic collaborations maintained by the surveyed stars within the region were found to be almost ubiquitous, closely followed in level by providing talent for the scientific labour market. However, the role of the star scientists is not restricted to these classic academic roles. More than two thirds of the investigated stars act as a source of skilled graduates for the regional industrial sector. Similar shares were found to also engage in joint R\&D projects with firms. But even rather specific activities like selling patents to firms and being a regional entrepreneur or a board member were reported by a substantial share of the top researchers.

To summarise, the findings reported in this paper confirm the view in the literature (see section 2) that a substantial knowledge transfer is related to international movements of (star) scientists. In contrast to some earlier work, in this paper a differentiated view of various modes that matter for knowledge transfer to scientific and industrial actors both at the interregional and intraregional level was provided. Finally, using a multivariate model, a set of factors was identified that have an influence on whether or not star scientists embed themselves in their location of choice by engaging in regional knowledge transfer activities. It 
was found that the international mobility background of stars does not suggest significant impact, i.e. mobile stars do not differ in their regional knowledge transfer activities from nonmobile stars. Other key variables had explanatory power; these being particularly interregional linkages to firms (pointing to a complementary relation between intraregional and interregional knowledge transfer activities), a focus on applied research and the stars' disciplines. Even more instructive was the finding that US-based stars do not differ in their intraregional knowledge transfer activities from top researchers located elsewhere.

Further empirical analyses are necessary to find out when and why location makes a difference and which characteristics of the regional environment of sending and receiving areas (such as elite universities, presence of innovative companies, high-tech sectors or industry clusters in fields related to the stars' disciplines, specific policy programmes, etc.) have an influence on intraregional and interregional knowledge transfer activities performed by top scientists. Another essential question concerns the impact of interregional and intraregional knowledge flows set off by stars on regional development of the sending and receiving areas. It was beyond the scope of this paper to measure the regional effects of knowledge transfer activities. Such an analysis is a key issue for future research and would essentially enhance our understanding of the regional consequences of international movements of scarce scientific brainpower. Finally, the results presented in this paper were based on rather small samples of elite researchers only. Analyses like those done in this paper could also be done for 'ordinary' scientists to see whether and how their mobility, knowledge transfer activities and regional impact differs from the pattern found for star scientists. 


\section{References}

ACKERS L. (2005) Promoting Scientific Mobility and Balanced Growth in the European Research Area, Innovation 18, 301-17.

ACKERS L. and GILL B. (2005) Attracting and Retaining 'Early Career' Researchers in English Higher Education Institutions, Innovation 18, 277-99.

AGRAWAL A., COCKBURN I. and McHALE J. (2006) Gone but not forgotten: Knowledge flows, labor mobility and enduring social relationships, Journal of Economic Geography $6,571-91$.

ARROW K. (1959) Economic Welfare and the Allocation of Resources for Invention, The RAND Corporation, Santa Monica.

BABA Y., SHICHIJO N. and SEDITA S. (2009) How do collaboration with universities affect firms' innovative performance? The role of "Pasteur scientists" in the advanced materials field, Research Policy 38, 756-64.

DÖRING T. and SCHNELLENBACH J. (2006) What do we know about geographical knowledge spillovers and regional growth? A survey of the literature, Regional Studies 40, 375-95.

FURUKAWA R. and GOTO A. (2006) Core scientists and innovation in Japanese electronics companies, Scientometrics 68, 227-40.

GILL B. (2005) Homeward bound? The experience of return mobility for Italian scientists, Innovation 18, 319-41.

HOROWITZ I. (1966) Some aspects of the effects of the regional distribution of scientific talent on regional economic activity, Management Science 13, 217-32. 
HUNTER R., OSWALD A. and CHARLTON B. (2009) The elite brain drain, The Economic Journal 119, 231-51.

JÖNS H. (2009) 'Brain circulation' and transnational knowledge networks: studying longterm effects of academic mobility to Germany, 1954-2000, Global Networks 9, 315-38.

KEEBLE D. (2000) Collective learning processes in European High-Technology Milieux, in KEEBLE D. and WILKINSON F. (Eds) High-technology clusters, networking and collective learning in Europe, pp. 199-229. Ashgate, Aldershot.

KERR W. (2008) Ethnic scientific communities and international technology diffusion, The Review of Economics and Statistics 90, 518-37.

LAUDEL G. (2003) Studying the brain drain: Can bibliometric methods help? Scientometrics $57,215-37$.

LAUDEL G. (2005) Migration currents among the scientific elite, Minerva 43, 377-95.

LAWTON SMITH H. and WATERS R. (2005) Employment mobility in high-technology agglomerations: the cases of Oxfordshire and Cambridgeshire, Area 37, 189-98.

MAHROUM S. (2003) Brain gain, brain drain: an international overview. Paper presented to the Austrian Ministry for Transport, Innovation and Technology Seminar, 22-23 August, Alpbach, Austria.

MEYER J.-B., KAPLAN D. and CHARUM J. (2001) Scientific nomadism and the new geopolitics of knowledge, International Social Science Journal 53, 309-21.

MOEN J. (2005) Is Mobility of Technical Personnel a Source of R\&D Spillovers? Journal of Labor Economics 23, 81-114. 
MOWERY D., NELSON R., SAMPAT B. and ZIEDONIS A. (2001) The growth of patenting and licensing by U.S. Universities: An Assessment of the Effects of the Bayh-Dole Act of 1980, Research Policy 30, 99-119.

OECD (2005) Trends in International Migration, OECD, Paris.

OECD (2006) Revised field of science and technology (FOS) classification in the Frascati manual, OECD, Paris.

OECD (2008) The global competition for talent. Mobility of the highly skilled, OECD, Paris.

OETTL A. and AGRAWAL A. (2008) International labour mobility and knowledge flow externalities, Journal of International Business Studies 39, 1242-60.

REGETS M. (2007) Research Issues in the International Migration of Highly Skilled Workers: A Perspective with Data from the United States, Science Resources Statistics Working Paper 07-203, National Science Foundation, Arlington (VA).

ROSENKOPF L. and ALMEIDA P. (2003) Overcoming Local Search Through Alliances and Mobility, Management Science 49, 751-66.

SAXENIAN A. (1994) Regional Advantage: Culture and Competition in Silicon Valley and Route 128, Harvard University Press, Cambridge (Mass.).

SAXENIAN A. (2005) From Brain Drain to Brain Circulation: Transnational Communities and Regional Upgrading in India and China, Comparative International Development $40,35-61$.

SCHARTINGER D., SCHIBANY A. and GASSLER H. (2001) Interactive relation between university and firms: Empirical evidence for Austria, Journal of Technology Transfer $26,255-68$. 
SCHILLER D. and REVILLA DIEZ J. (2010) Local embeddedness of knowledge spillover agents: Empirical evidence from German star scientists, Papers in Regional Science 89, 275-94.

SKELDON R. (2009) Of skilled migration, brain drains and policy responses, International Migration 47, 3-29.

THORN K. and HOLM-NIELSEN L. (2008) International Mobility of Researchers and Scientists: Policy Options for Turning a Drain into a Gain, in SOLIMANO A. (Ed) The International Mobility of Talent, pp. 145-67. Oxford University Press, Oxford.

TÖDTLING F., LEHNER P. and TRIPPL M. (2006) Innovation in knowledge intensive industries: The nature and geography of knowledge links, European Planning Studies $14,1035-58$.

WILLIAMS A. (2007) International labour migration and tacit knowledge transactions: a multi-level perspective, Global Networks 7, 29-50.

WILLIAMS A., BALAZ V. and WALLACE C. (2004) International Labour Mobility and Uneven Regional Development in Europe, European Urban and Regional Studies 11, 27-46.

ZUCKER L. and DARBY M. (2006) Movements of Star Scientists and Engineers and HighTech Firm Entry, NBER Working Paper No. 12172, National Bureau of Economic Research, Cambridge (MA).

ZUCKER L., DARBY M. and ARMSTRONG J. (2002) Commercializing Knowledge: University Science, Knowledge Capture and Firm Performance in Biotechnology, Management Science 48, 138-53. 
ZUCKER L., DARBY M. and BREWER M. (1998) Intellectual Human Capital and the Birth of U.S. Biotechnology Enterprises', American Economic Review 88, 290-306. 
Figure

Figure 1: Knowledge link model

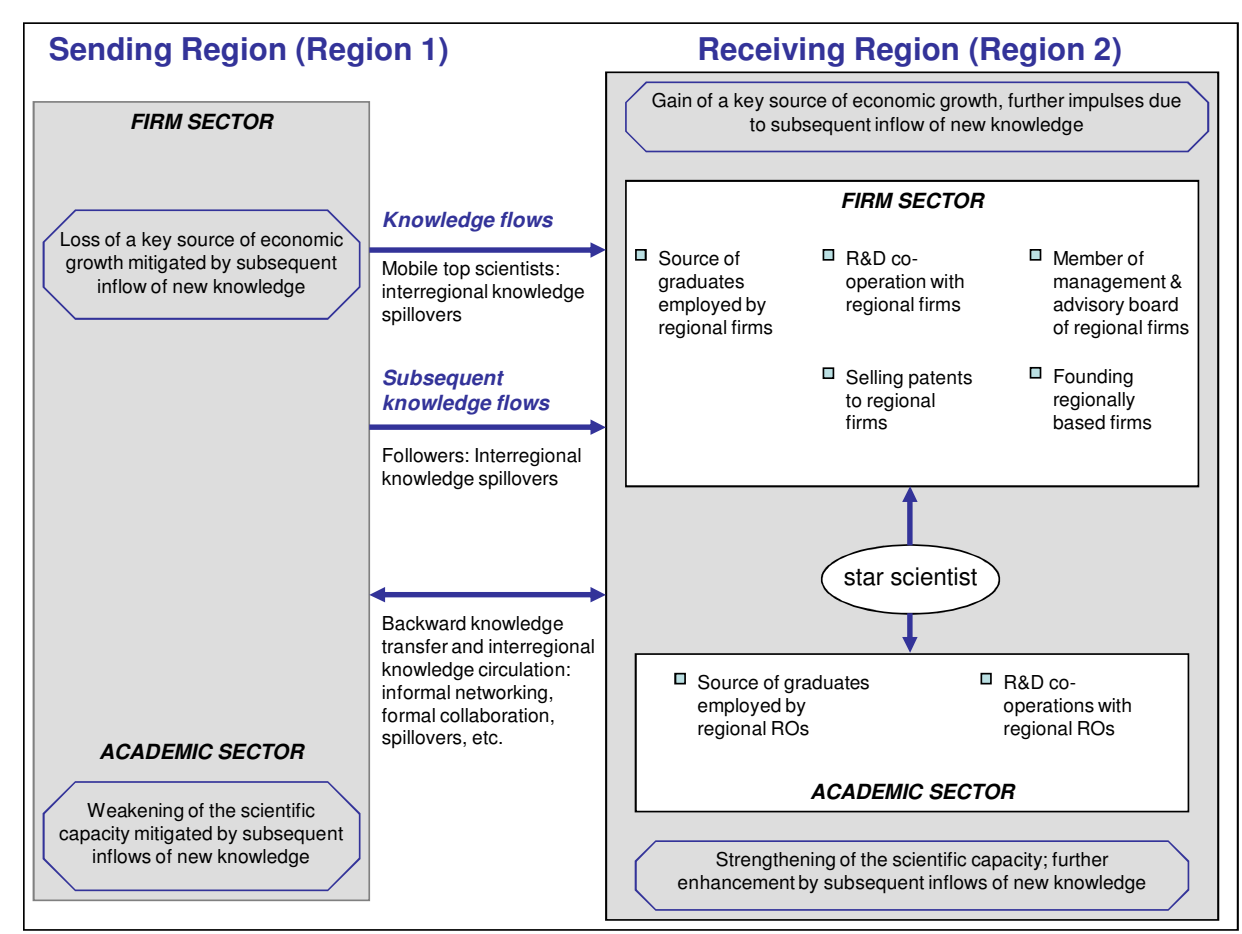




\begin{tabular}{|c|c|c|c|c|c|}
\hline & & $\begin{array}{r}\text { Total } \\
(\mathrm{N}=720)\end{array}$ & $\begin{array}{l}\text { Expats } \\
(\mathrm{N}=181)\end{array}$ & $\begin{array}{l}\text { Returnees } \\
(\mathrm{N}=194)\end{array}$ & $\begin{array}{l}\text { Non- } \\
\text { Movers } \\
(\mathrm{N}=345)\end{array}$ \\
\hline \multirow[t]{3}{*}{ Gender } & Female & 5.6 & 5.0 & 4.1 & 6.7 \\
\hline & Male & 92.6 & 92.8 & 94.3 & 91.6 \\
\hline & Missing & 1.8 & 2.2 & 1.5 & 1.7 \\
\hline Year of Birth & Mean & & 1946.7 & 1945.7 & 1946.9 \\
\hline Type of & University & 70.4 & 71.8 & 68.6 & 70.7 \\
\hline \multirow[t]{4}{*}{ Institution } & Non-university research entity & 18.3 & 17.1 & 20.6 & 17.7 \\
\hline & Corporate research unit & 2.1 & 2.2 & 1.0 & 2.6 \\
\hline & Other & 5.8 & 6.1 & 6.7 & 5.2 \\
\hline & Missing & 3.3 & 2.8 & 3.1 & 3.8 \\
\hline Type of & Exclusively / mostly basic research & 50.5 & 44.2 & 53.6 & 52.2 \\
\hline \multirow[t]{5}{*}{ Research } & Rather basic research & 11.3 & 11.6 & 13.9 & 9.6 \\
\hline & Basic and applied research & 22.1 & 27.1 & 19.6 & 20.9 \\
\hline & Rather applied research & 4.7 & 5.0 & 4.1 & 4.9 \\
\hline & Exclusively / mostly applied research & 9.8 & 10.0 & 7.7 & 10.7 \\
\hline & Missing & 1.7 & 2.2 & 1.0 & 1.7 \\
\hline Research & Natural Sciences & 53.3 & 56.4 & 56.2 & 50.1 \\
\hline \multirow[t]{4}{*}{ Discipline } & Engineering \& Technology & 10.1 & 13.8 & 8.8 & 9.0 \\
\hline & Medical \& Health Sciences & 23.3 & 16.0 & 24.2 & 26.7 \\
\hline & Agriculture Sciences & 3.1 & 4.4 & 4.1 & 1.7 \\
\hline & Social Sciences & 7.6 & 7.2 & 5.2 & 9.3 \\
\hline
\end{tabular}

Tables

Table 1: Sample characteristics (\% of star scientists) 
Missing

Expatriates: Mean (Min. 0.7, Max. 60): 29.5
Years spent
abroad

$1-10$ years

$11-20$ years

$21-30$ years

$31-40$ years

More than 40 years

Missing

2.5

2.2

1.5

3.2

11.6

8.8

29.8

30.9

16.6

2.2

\footnotetext{
Returnees: $\quad$ Mean (Min. 0.5, Max. 40): 5.9

Years spent

abroad
}

$\begin{array}{lcc}\text { Less than 1 year } & - & 1.6 \\ 1-3 \text { years } & - & 49.0 \\ 4-10 \text { years } & - & 32.5 \\ \text { More than } 10 \text { years } & - & 12.9 \\ \text { Missing } & - & 4.1\end{array}$


Table 2: Modes of knowledge transfer to scientific community at the prior location (\% of mobile star scientists)

\begin{tabular}{lcccc}
\hline & Expatriates $(\mathrm{N}=181)$ & \multicolumn{2}{c}{ Returnees $(\mathrm{N}=194)$} \\
& $\%$ & $\%($ strong) & $\%$ & $\%$ (strong) \\
\hline Research co-operation & 60.8 & $(25.4)$ & 79.4 & $(50.0)$ \\
Contract research & 51.4 & $(18.8)$ & 71.7 & $(31.5)$ \\
Co-operation in consulting and licensing & 30.9 & $(7.7)$ & 40.1 & $(9.2)$ \\
Joint publications & 64.1 & $(18.8)$ & 79.0 & $(43.8)$ \\
Joint patents & 8.8 & $(0.0)$ & 19.6 & $(3.1)$ \\
Recruitment of scientists and research professionals & 48.1 & $(6.1)$ & 56.7 & $(10.3)$ \\
Joint participation in workshops and other events & 67.4 & $(19.9)$ & 77.3 & $(41.2)$ \\
Joint attendance of international scientific conferences & 70.7 & $(30.4)$ & 81.5 & $(54.7)$ \\
Research visits and staff exchange & 70.2 & $(21.0)$ & 82.4 & $(37.6)$
\end{tabular}

Strong: frequently or regularly (as opposed to weak: seldom or occasionally) 
Table 3: Modes of knowledge transfer to firms at the prior location (\% of mobile star scientists)

\begin{tabular}{lcccc}
\hline & Expatriates (N=181) & Returnees (N=194) \\
& $\%$ & $\%$ (strong) & $\%$ & $\%$ (strong) \\
\hline Research co-operation & 15.0 & $(5.6)$ & 26.3 & $(6.7)$ \\
Contract research & 12.2 & $(6.1)$ & 22.2 & $(6.2)$ \\
Consulting services & 16.0 & $(5.0)$ & 24.3 & $(8.8)$ \\
Licensing agreements & 7.8 & $(2.2)$ & 14.9 & $(2.5)$ \\
Joint publications & 11.7 & $(2.8)$ & 21.6 & $(3.6)$ \\
Joint patents & 5.1 & $(1.2)$ & 8.7 & $(0.5)$ \\
Recruitment of scientists and research professionals & 9.4 & $(1.1)$ & 11.3 & $(1.0)$ \\
Joint participation in industry fairs and exhibitions & 3.9 & $(0.0)$ & 6.6 & $(1.5)$ \\
Joint participation in workshops and other events & 12.2 & $(3.9)$ & 20.5 & $(4.6)$ \\
Joint attendance of international scientific conferences & 12.8 & $(5.6)$ & 24.2 & $(7.2)$ \\
Research visits and staff exchange & 13.8 & $(5.0)$ & 24.8 & $(2.1)$ \\
\hline Strong: frequently or regularly (as opposed to weak: seldom & & & & \\
\hline
\end{tabular}

Strong: frequently or regularly (as opposed to weak: seldom or occasionally) 
Table 4: Modes of intraregional knowledge transfer (\% of star scientists)

\begin{tabular}{|c|c|c|c|c|c|c|}
\hline & \multicolumn{2}{|c|}{ Expatriates } & \multicolumn{2}{|c|}{ Returnees } & \multicolumn{2}{|c|}{ Non-mobile stars } \\
\hline & $\%$ & $\begin{array}{r}\% \\
\text { strong }\end{array}$ & $\%$ & $\begin{array}{r}\% \\
\text { strong }\end{array}$ & $\%$ & $\%$ strong \\
\hline \multicolumn{7}{|l|}{ Academic Sector: } \\
\hline Academic Collaboration & 98.3 & $61.8^{(1)}$ & 99.5 & $67.0^{(1)}$ & 98.2 & $64.3^{(1)}$ \\
\hline $\begin{array}{l}\text { Source of talent for scientific } \\
\text { labour market }\end{array}$ & 84.8 & $21.9^{(2)}$ & 88.9 & $18.9^{(2)}$ & 86.9 & $25.5^{(2)}$ \\
\hline Industrial Sector: & & & & & & \\
\hline Source of highly qualified & 66.7 & $14.1^{(2)}$ & 78.7 & $19.1^{(2)}$ & 73.6 & $13.8^{(2)}$ \\
\hline workers & & & & & & \\
\hline R\&D projects with firms & 73.0 & $25.3^{(1)}$ & 75.8 & $27.4^{(1)}$ & 79.8 & $26.0^{(1)}$ \\
\hline Selling patents to firms & 27.8 & $5.1^{(1)}$ & 32.3 & $3.2^{(1)}$ & 37.9 & $5.0^{(1)}$ \\
\hline Entrepreneur & 15.2 & & 14.2 & & 13.9 & \\
\hline Member of firm board & 28.2 & & 27.2 & & 25.4 & \\
\hline
\end{tabular}


Table 5: Definition of dependent and explanatory variables

\begin{tabular}{|c|c|}
\hline Variable name & Variable description \\
\hline \multicolumn{2}{|l|}{ Dependent variables: } \\
\hline $\mathrm{ACO}$ & $\begin{array}{l}\text { A binary variable which is } 1 \text { if the respondent engages in the regional knowledge } \\
\text { transfer activity 'academic collaboration' and } 0 \text { if not }\end{array}$ \\
\hline SLM & $\begin{array}{l}\text { A binary variable which is } 1 \text { if the respondent engages in the regional knowledge } \\
\text { transfer activity 'source of talent for scientific labour market' and } 0 \text { if not }\end{array}$ \\
\hline ILM & $\begin{array}{l}\text { A binary variable which is } 1 \text { if the respondent engages in the regional knowledge } \\
\text { transfer activity 'source of highly qualified workers' and } 0 \text { if not }\end{array}$ \\
\hline RDP & $\begin{array}{l}\text { A binary variable which is } 1 \text { if the respondent engages in the regional knowledge } \\
\text { transfer activity ' } R \& D \text { projects with firms' and } 0 \text { if not }\end{array}$ \\
\hline PAT & $\begin{array}{l}\text { A binary variable which is } 1 \text { if the respondent engages in the regional knowledge } \\
\text { transfer activity 'selling patents to firms' and } 0 \text { if not }\end{array}$ \\
\hline ENT & $\begin{array}{l}\text { A binary variable which is } 1 \text { if the respondent engages in the regional knowledge } \\
\text { transfer activity 'entrepreneur' and } 0 \text { if not }\end{array}$ \\
\hline MEM & $\begin{array}{l}\text { A binary variable which is } 1 \text { if the respondent engages in the regional knowledge } \\
\text { transfer activity 'member of firm board' and } 0 \text { if not }\end{array}$ \\
\hline Explanatory variables: & \\
\hline IL_Sci & $\begin{array}{l}\text { Dummy variable set to } 1 \text { if the respondent maintains international knowledge } \\
\text { links to a scientific organisation at her/his prior location }\end{array}$ \\
\hline IL_Ind & $\begin{array}{l}\text { Dummy variable set to } 1 \text { if the respondent maintains international knowledge } \\
\text { links to a firm at her/his prior location }\end{array}$ \\
\hline Returnee & Dummy variable set to 1 if the respondent is a returnee (default - non-mover) \\
\hline Expatriate & Dummy variable set to 1 if the respondent is an expatriate (default - non-mover) \\
\hline Inst_NonUniv & $\begin{array}{l}\text { Dummy variable set to } 1 \text { if the respondent is employed in a non-university } \\
\text { research unit (default - university) }\end{array}$ \\
\hline Inst_Corp & $\begin{array}{l}\text { Dummy variable set to } 1 \text { if the respondent is employed in a corporate research } \\
\text { unit (default - university) }\end{array}$ \\
\hline Inst_Other & Dummy variable set to 1 if the respondent is employed in another non-university \\
\hline
\end{tabular}


1

2

3

4

5

6

7

9

10

11

12

13

14

15

16

17

18

19

20

21

22 research unit (default - university)

Type Research

Indicator which is larger the more applied the respondent's research is

SG_Nat

Dummy variable set to 1 if the respondent is in natural sciences (default - social sciences)

SG_Eng

Dummy variable set to 1 if the respondent is in engineering \& technology

(default - social sciences)

SG_Med

Dummy variable set to 1 if the respondent is in medical $\&$ health sciences

(default - social sciences)

SG_Agr

Dummy variable set to 1 if the respondent is in agricultural sciences (default social sciences)

Gender

Dummy variable set to 1 for a female respondent (default - male)

Age

Age2

US

Europe
The respondent's age in years

The respondent's age in years squared (divided by 1,000) to allow for a U-

shaped or inverse U-shaped relationship

Dummy variable set to one if the star is located in a US region (default - rest of the world)

Dummy variable set to one if the star is located in a European region (default rest of the world) 
Table 6: Binary logit model

\begin{tabular}{|c|c|c|c|c|c|c|c|}
\hline & ACO & SLM & ILM & RDP & PAT & ENT & MEM \\
\hline IntLink_Sci & -0.38 & -0.61 & -0.52 & -0.53 & $-0.65 *$ & $-0.79 *$ & -0.02 \\
\hline IntLink_Ind & 0.22 & & 0.07 & 0.51 & $0.85 * * *$ & $1.24 * * *$ & $1.18 * * *$ \\
\hline Returnee & 0.33 & 1.66 & 0.52 & 0.07 & 0.07 & 0.32 & -0.20 \\
\hline Expatriate & 0.18 & 0.70 & 0.02 & -0.12 & -0.12 & 0.43 & -0.03 \\
\hline Inst_NonUniv & $-0.69 * *$ & 0.13 & $-0.68 * * *$ & 0.23 & -0.01 & -0.44 & -0.22 \\
\hline Inst_Corp & $-1.16 *$ & & -1.08 & 0.81 & 0.12 & $1.79 * * *$ & 0.96 \\
\hline Inst_Other & -0.33 & -1.47 & -0.44 & 0.38 & $0.81 * *$ & 0.42 & 0.41 \\
\hline Type Research & 0.03 & -0.06 & $0.19 * * *$ & $0.37 * * *$ & $0.13 * *$ & $0.36 * * *$ & $0.22 * * *$ \\
\hline SG_Nat & -1.01 & 0.79 & 0.13 & $1.06 * * *$ & $1.96 * * *$ & 0.24 & -0.11 \\
\hline SG_Eng & -0.63 & & $1.28 * *$ & $2.43 * * *$ & $2.86 * * *$ & -0.64 & 0.15 \\
\hline SG_Med & -0.46 & 1.50 & 0.28 & $1.48 * * *$ & $2.70 * * *$ & 0.68 & 0.61 \\
\hline SG_Agr & -1.04 & & -0.76 & $1.36 * *$ & 1.19 & -0.89 & -1.16 \\
\hline Gender & 0.23 & 0.90 & $1.12 * * *$ & $0.92 * *$ & 0.68 & 0.14 & 0.11 \\
\hline Age & 0.05 & -0.09 & 0.07 & 0.00 & -0.10 & 0.01 & -0.04 \\
\hline Age2 & -0.00 & 0.00 & -0.00 & -0.00 & 0.00 & -0.00 & 0.00 \\
\hline US & -0.42 & $1.91 *$ & $-0.45 *$ & -0.05 & 0.12 & 0.20 & 0.28 \\
\hline Europe & 0.62 & -0.13 & 0.50 & 0.50 & -0.03 & 0.13 & 0.28 \\
\hline Constant & 0.66 & 4.75 & -3.94 & -2.61 & -0.97 & -3.82 & -1.50 \\
\hline Obs. & 650 & 484 & 654 & 654 & 647 & 652 & 654 \\
\hline Likelihood & 24.76 & 11.41 & 88.45 & 88.45 & 88.29 & 74.68 & 70.58 \\
\hline P(LR-Test) & 0.10 & 0.58 & 0.00 & 0.00 & 0.00 & 0.00 & 0.00 \\
\hline Pseudo R2 & 0.05 & 0.14 & 0.13 & 0.13 & 0.11 & 0.14 & 0.09 \\
\hline
\end{tabular}




\section{Annex}

Table 7: Sending and receiving regions of expatriates

\begin{tabular}{|c|c|c|c|c|c|}
\hline & Number & $\%$ & & Number & $\%$ \\
\hline Receiving Regions & of stars & (cum.) & Sending Regions & of stars & (cum.) \\
\hline Cambridge, MA (US) & 6 & 3.7 & London (UK) & 13 & 8.0 \\
\hline Stanford (US) & 5 & 6.8 & Buenos Aires (AR) & 5 & 11.1 \\
\hline Boulder (US) & 4 & 9.3 & Christchurch (NZ) & 5 & 14.2 \\
\hline Chicago (US) & 4 & 11.8 & Cambridge (UK) & 4 & 16.7 \\
\hline Davis (US) & 4 & 14.3 & Melbourne (AU) & 4 & 19.1 \\
\hline New York (US) & 4 & 16.8 & Paris (FR) & 4 & 21.6 \\
\hline Philadelphia (US) & 4 & 19.3 & Toronto (CA) & 4 & 24.1 \\
\hline Princeton (US) & 4 & 21.7 & Johannesburg (ZA) & 3 & 25.9 \\
\hline Lausanne $(\mathrm{CH})$ & 3 & 23.6 & Munich (DE) & 3 & 27.8 \\
\hline London (UK) & 3 & 25.5 & Oxford (UK) & 3 & 29.6 \\
\hline Oxford (UK) & 3 & 27.3 & Prague $(\mathrm{CZ})$ & 3 & 31.5 \\
\hline Vancouver (CA) & 3 & 29.2 & Sydney (AU) & 3 & 33.3 \\
\hline 19 regions each hosting 2 stars & 38 & 52.8 & Tokyo (JP) & 3 & 35.2 \\
\hline 76 regions each hosting 1 star & 76 & 100.0 & Vienna (AT) & 3 & 37.0 \\
\hline \multirow[t]{3}{*}{ Total } & 161 & & 8 regions each sending 2 stars & 16 & 46.9 \\
\hline & & & 86 regions each sending 1 star & 86 & 100.0 \\
\hline & & & Total & 162 & \\
\hline Missing: receiving regions of 20 & & & \multicolumn{3}{|l|}{ Missing: sending regions of 19} \\
\hline expats & & & expats & & \\
\hline
\end{tabular}


Table 8: Receiving Regions and Sending Regions of Returnees

\begin{tabular}{|c|c|c|c|c|c|}
\hline & Number & $\%$ & & Number & $\%$ \\
\hline Receiving Regions & of stars & (cum.) & Sending Regions & of stars & (cum.) \\
\hline Kyoto (JP) & 6 & 3.4 & New York (US) & 8 & 4.4 \\
\hline Tokyo (JP) & 6 & 6.8 & Berkeley (US) & 6 & 7.8 \\
\hline Munich (DE) & 5 & 9.6 & Canberra (AU) & 6 & 11.1 \\
\hline Copenhagen (DK) & 4 & 11.9 & Boston (US) & 6 & 14.4 \\
\hline London (UK) & 4 & 14.1 & London (UK) & 5 & 17.2 \\
\hline Seattle (US) & 4 & 16.4 & Bethesda (US) & 4 & 19.4 \\
\hline Toronto (CA) & 4 & 18.6 & Chicago (US) & 4 & 21.7 \\
\hline Zurich $(\mathrm{CH})$ & 4 & 20.9 & Melbourne (AU) & 4 & 23.9 \\
\hline Boulder (US) & 3 & 22.6 & Sydney (AU) & 4 & 26.1 \\
\hline Cambridge (UK) & 3 & 24.3 & Los Angeles (US) & 4 & 28.3 \\
\hline Canberra (AU) & 3 & 26.0 & Cambridge (UK) & 3 & 30.0 \\
\hline Leuven (BE) & 3 & 27.7 & Copenhagen (DK) & 3 & 31.7 \\
\hline Norwich (UK) & 3 & 29.4 & Palo Alto (US) & 3 & 33.3 \\
\hline Sydney (AU) & 3 & 31.1 & San Francisco (US) & 3 & 35.0 \\
\hline Tel Aviv (IL) & 3 & 32.8 & Stanford (US) & 3 & 36.7 \\
\hline Wuerzburg (DE) & 3 & 34.5 & Toronto (CA) & 3 & 38.3 \\
\hline 14 regions each hosting 2 stars & 28 & 50.3 & Zurich $(\mathrm{CH})$ & 3 & 40.0 \\
\hline 88 regions each hosting 1 star & 88 & 100.0 & Stockholm (SE) & 3 & 41.7 \\
\hline \multirow[t]{3}{*}{ Total } & 177 & & 25 regions each sending 2 stars & 50 & 69.4 \\
\hline & & & 55 regions each sending 1 star & 55 & 100.0 \\
\hline & & & Total & 180 & \\
\hline Missing: receiving regions of 17 & & & Missing: sending regions of 14 & & \\
\hline returnees & & & returnees & & \\
\hline
\end{tabular}


Regional Concentrations of Non-movers

\begin{tabular}{|c|c|c|}
\hline & Number of & \\
\hline & stars & $\%$ (cumul.) \\
\hline New York (US) & 13 & 4.3 \\
\hline Boston (US) & 8 & 6.9 \\
\hline Austin (US) & 7 & 9.2 \\
\hline Bethesda (US) & 7 & 11.4 \\
\hline Baltimore (US) & 6 & 13.4 \\
\hline Chicago (US) & 6 & 15.4 \\
\hline London (UK) & 6 & 17.3 \\
\hline Los Angeles (US) & 6 & 19.3 \\
\hline Atlanta (US) & 5 & 20.9 \\
\hline Oxford (UK) & 5 & 22.5 \\
\hline Tokyo (JP) & 5 & 24.2 \\
\hline Ann Arbor (US) & 4 & 25.5 \\
\hline Cambridge, MA (US) & 4 & 26.8 \\
\hline Charlottesville (US) & 4 & 28.1 \\
\hline Davis (US) & 4 & 29.4 \\
\hline Durham (US) & 4 & 30.7 \\
\hline Irvine (US) & 4 & 32.0 \\
\hline Madison (US) & 4 & 33.3 \\
\hline Oak Ridge (US) & 4 & 34.6 \\
\hline Philadelphia (US) & 4 & 35.9 \\
\hline Cambridge (UK) & 3 & 36.9 \\
\hline Kyoto (JP) & 3 & 37.9 \\
\hline Lund (SE) & 3 & 38.9 \\
\hline Millbrook (US) & 3 & 39.9 \\
\hline Nashville (US) & 3 & 40.8 \\
\hline New Haven (US) & 3 & 41.8 \\
\hline Pasadena (US) & 3 & 42.8 \\
\hline
\end{tabular}


Salt Lake City (US)

Seattle (US)

Stanford (US)

3

32 cities each hosting 2 stars

Missing: home regions of 39

non-movers

\section{Notes}

${ }^{1}$ The knowledge link model suggested in this paper does not consider unintended spillovers which may result from the mere presence of star scientists in a region. Such spillovers do not require any form of engagement or activities by top researchers and might, thus, be observable even for 'isolated star scientists', i.e. stars who lack any ties at the regional level. The argument is not that unintended spillovers cannot play a critical role in regional development. Nevertheless, the focus of this paper is only on potential contributions by star scientists to regional dynamics which require deliberate efforts and actions, and, therefore, a certain degree of regional 'embeddedness' of stars.

${ }^{2}$ This is in line with the results of a recent study of 158 of the world's most highly-cited physicists who found that $50 \%$ of these stars work outside their country of birth (HUNTER et al., 2009).

${ }^{3}$ Responses by stars who indicated that they are retired, have established their own firm, work for the government or do consulting are summarised under the category 'other'.

${ }^{4}$ The 21 subject categories have been classified according to the Frascati Manual (OECD, 2006) into five broader fields of science and technology.

${ }^{5}$ Similar models were used for analysing the three groups of star scientists separately. In all three models the explanatory variables 'expatriate' and 'returnee' have been skipped. In the models dealing with expatriates and returnees the variable 'years spent abroad' has been added. Results are very similar to those reported in section 4.3. The same factors as those found for the overall sample turned out to be relevant. The model for expatriates showed that additionally the period of time these stars have already spent abroad has a positive and significant 
influence on the activities 'R\&D projects with firms', 'source of talent for scientific labour market' and 'source of highly-qualified workers'. The more years expats have already spent in their new location, the likelier it is that they perform these activities, implying that embedding in the new location via these activities requires a substantial period of time. 